\title{
En octubre no hay milagros, de Oswaldo Reynoso
}

Resumen

El autor comenta la novela En octubre no hay milagros, del escritor peruano Oswaldo Reynoso. Nos dice que todo el interés de esta novela radica exclusivamente en su forma o estructura idiomática y, en ese sentido, se trata sin duda de una verdadera obra maestra. Pero esto significa, además, que entraña dificultades sin fin, pues el arte conlleva esa dificultad de que hablaba G. Steiner.

Palabras clave: En octubre no hay milagros, Oswaldo Reynoso, estructura idiomática, literatura peruana

\section{Abstract}

The author talks on Oswaldo Reynoso's En octubre no hay milagros. He says that interest on this novel is based exclusively in the language structure and, in that way, is a real master piece. But this means a difficulty related with one kind of difficulty analyzed by G. Steiner.

Key words: En octubre no hay Milagros, Oswaldo Reynoso, Language structure, Peruvian literature

$\mathrm{N}$ o quiero hablar aquí del contenido de esta novela en el sentido de lo «novedoso» o de lo «interesante». Lo primero que debemos hacer, para entendernos, es intentar distinguir entre dos aspectos que no suelen tenerse comúnmente en cuenta. En primer lugar, que eso que llamamos textos no constituye una clase única, sino, como mínimo, dos. $\mathrm{Y}$ dos clases muy bien diferenciadas, aunque tales diferencias se ignoran con frecuencia en el uso común del lenguaje. Quiero, pues, hacer una división en el conjunto de esas cosas que llamamos textos, poniendo la atención en la forma o estructura del significado. Cuando se trata de un texto literario no hay más remedio que distinguir entre dos realidades 
totalmente diferentes, aunque denominadas en general de la misma manera. Yo creo que se debe hablar de texto o de «texto en sí», frente a «informe» o «relato», por ejemplo. Si hablo aquí de "texto en sí» solo quiero diferenciar el objeto lingüístico como forma, es decir, como algo que no se puede traducir ni expresar de una manera diferente de la que tiene. Digamos que cada «texto en sí» es diferente de cualquiera otro, en tanto que cada informe o relato pueden decirse, sin daño, de mil maneras, o traducirse a otras lenguas, pues lo que interesa en ellos no es la forma sino el referente; es decir, 'lo que se cuenta', 'la supuesta realidad contada'. El Hamlet de Shakespeare, por ejemplo, no se puede traducir, en el buen sentido de esta palabra, porque cualquier traducción no será nunca más que una simple interpretación del traductor. Y no digamos nada de la poesía: ¿quién se atrevería a traducir un poema de César Vallejo, sin aclarar, de camino, que aquello es «lo que él ha entendido o creído entender», pero no el significado del original, que es, sin duda, ese texto mismo? En las traducciones de textos literarios lo que leemos no es nunca el original — «el texto en sí»—, sino la versión del traductor, mejor o peor hecha. Y ¿quién se atrevería a traducir a otra lengua En octubre no hay milagros, con la pretensión de lograr su significado idiomático propiamente dicho? No hay duda de que esta novela se traducirá —y seguramente muy pronto—, pero ya no consistirá en este mismo texto que tenemos aquí, sino en lo que haya visto el traductor, inteligente o no. No se tratará ya de una novela de Oswaldo Reynoso, sino de lo que ha entendido tal o cual lector. Y, además, en el caso particular de esta obra, la traducción resulta tan difícil como es la traducción de la poesía, en la que solo encontraremos lo que el traductor cree haber visto y no lo que realmente hay allí, que es la palabra en su estado prístino. La sinonimia no existe y lo que así suele llamarse es la coincidencia de dos palabras distintas señalando un mismo objeto real. Y así, dos palabras como perro y can, consideradas siempre como sinónimos no lo son ni pueden serlo por el simple hecho de que no pueden alternar en todos sus contextos posibles: llevar una vida perra, pero no llevar una vida can.

Nos encontramos en esta novela de Reynoso con un verdadero texto, con un texto que solo puede ser como es, por lo que naturalmente será imposible de traducir a cualquier otra lengua. En octubre no hay milagros es un "texto en sí», un fruto natural de la lengua y no un informe periodístico de la famosa procesión del Señor de los Milagros o un simple relato de la misma.

Todo el interés de esta novela de Oswaldo Reynoso radica exclusivamente en su forma o estructura idiomática y, en ese sentido, se trata sin duda de una verdadera obra 
maestra. Pero esto significa, además, que entrańa dificultades sin fin, pues el arte conlleva esa dificultad de que hablaba G. Steiner ${ }^{1}$. Solo el lenguaje banal es ajeno a la dificultad del «texto en sí», del texto que exige del lector un nuevo, un renovado esfuerzo, para cada nueva lectura. Los textos que no poseen esta propiedad no son verdaderos textos, sino simples informes o relatos, siempre traducibles porque solo son los nombres o los retratos de cosas o situaciones conocidas.

Pero las dificultades no están solo en la inmensa cantidad de vocabulario coloquial y popular de Lima que el texto contiene y que requiere un apéndice léxico explicativo ${ }^{2}$, sino - y en la misma medida - en el uso del vocabulario común del español general, que el autor emplea aquí con una originalidad creativa que explora todos los sentidos posibles de las palabras, más allá de los usos comunes o vulgares ${ }^{3}$. Y esa exploración de la variación semántica, llevándola más allá de los usos habituales, que es la principal cualidad de lo poético, es uno de los valores más apreciables de la novela de Reynoso. A mí, como lingüista, me interesa en especial esta dimensión de su obra, y como no puedo hacer un comentario de todos y de cada uno de los usos ejemplares que encuentro en ella, dedicaré estas notas a una pequeña selección entre algunas de las infinitas muestras que el libro ofrece. Como no soy especialista en Literatura Hispanoamericana no hablaré de la ubicación literaria de las obras de Reynoso: a mí me interesa, y mucho, lo verdaderamente esencial, que es la forma del lenguaje en que está escrita En octubre no hay milagros. Un texto literario solo es forma;

1 "¿A qué nos referimos al decir "este poema o este pasaje en este poema es dificil"? ¿Cómo puede el acto de lenguaje, cargado al máximo con el intento de comunicación, llegar a tocar al oyente o al lector en lo más íntimo, ser opaco, resistente a la inmediatez y a la comprensión, si esto es lo que queremos decir con "dificultad"? La dificultad está en la esencia del texto y no, como creen algunos, en la transparencia de sus posibles referentes. El trabajo citado aparece en Sobre la dificultad y otros ensayos, Fondo de Cultura Económica, México, 2001, pp. 37-81.

2 La lingüista Luisa Portilla Durand, catedrática de la Universidad de San Marcos, ha trabajado muy seriamente sobre los aspectos léxicos de la obra de Reynoso y, asimismo, ha publicado trabajos importantes sobre el léxico peruano y, además, ha desarrollado, a lo largo del 2009, un estudio de las definiciones de todo el léxico de la novela Los Inocentes y otro, a lo largo del 2010, sobre el léxico de En octubre no hay milagros.

3 Entiéndase aquí vulgar como lo propio del vulgo, de la gente no educada, de la gente común. Hago esta precisión porque, en general, en América, las variantes semánticas de vulgar son negativas. Particularmente, en el Perú, la acepción más generaliza de vulgar equivale a soez, ya sea para referirse a una palabra o a una persona. Compete a los profesores de Lengua explicar detalladamente estas diferencias de uso y hacer ver cómo en las lenguas la variación semántica es siempre explicable y, sobre todo, aceptable; partiendo, claro está, de un principio fundamental de la lingüística: una palabra puede tener múltiples y diversos usos, pero solo un único significado. 
es decir, «texto en sí». Todo lo demás son opiniones y solo opiniones, seguramente útiles, pero siempre formalmente ajenas el texto en sí.

De todas maneras, hay que tener siempre presente que el autor marca tipográficamente los dos puntos de vista esenciales que dominan en el texto. Hay, en efecto, una separación física entre el punto de vista del narrador y los puntos de vista de los personajes, que aparecen como monólogos interiores. El punto de vista del narrador se encuentra siempre en redonda, como se verá en los ejemplos que uso para mi análisis. Lo que piensa, siente o sueña cada personaje, aparece siempre en cursiva.

Y lo que me parece no ya interesante, sino esencial, es la sabiduría «idiomática» con que el autor distribuye y combina los sentidos habituales de las palabras —es decir, la variación semántica propiamente dicha- y, sobre todo, cómo relaciona entre sí esos matices en busca de nuevas posibilidades expresivas. Por ejemplo, en el comienzo de la novela, nos encontramos con una variada y atractiva distribución de las variantes semánticas del adjetivo morado, que, además de señalar el color de las vestimentas de los devotos de la procesión del Señor de los Milagros, se repite insistentemente en los primeros párrafos de la novela: ¿qué sugiere, por ejemplo, ese «morado dulce en alfombra»? ¿Qué remolino de connotaciones se reúnen en ese brillante inicio del texto?

«Morado. Ácido morado sobre cielo de ceniza. Sucia la niebla podrida en pescado. Morado dulce en alfombra. Morado turbio y ondulante en cuerpos morenos. Morado tibio en mañana fría: mojada.»

Morado lo abarca todo en ese párrafo para, marcar luego, el color de lo que hay «sobre» ese «cielo de ceniza» y no «bajo él», marcando así la especial y absoluta relevancia del morado y del espacio en que se manifiesta. La suciedad está por encima y es también aquí, como hemos visto, morada, de color clerical, pues estamos ante la imagen de una procesión. Y, luego, ese morado dulce que se extiende por el suelo sucio y que, turbio -turbiamente-, marca los cuerpos. Luego, el morado de las personas, sensual escalofrío tibio en el frío de la mańana mojada. Hay en esos usos de morado, sin embargo, no solo el colorido, eclesiástico o no, sino también un cierto «sentimiento de atracción», un innegable regusto sensual. El libro está escrito con un fuerte sentido crítico; pero, al mismo tiempo, con un llamativo sentimiento afectuoso — diría yo amoroso — que se oculta bajo la capa de lo feo o de lo siniestro. Esa afectuosidad se expresa siempre negativamente — por contraste_, como vemos cuando pone el morado seguido de esa "sucia la niebla podrida en pescado", 
justamente antes de un nuevo y sensual morado que vamos pisando: «morado dulce en alfombra».

\section{MIGUEL}

$\mathrm{Y}$

de ahí se pasa al "punto de vista» de Miguel, el hijo de don Lucho, a su pensamiento, naturalmente en cursiva: "iPor qué se vestirán de morado? El morado es triste y más aún bajo el cielo nublado. Blanco o rojo sobre rostros morenos: mejor en cielo gris, bonito. Pero ese morado, ese morado, morado de pena, de muerto: da ganas de llorar. Uno se siente triste. Sufrido: iya comienzo con lo mismo! Pretextos no faltan para llorar cuando estoy borracho. Ahora será el color morado el que me dé pena.»

De vuelta al morado, que sigue dominando toda la escena. El morado es eclesiástico y caracteriza, naturalmente, el espacio en que transcurre todo. Pero, para ese Miguel que se rebela, el morado es malo —ese morado, ese morado, morado de pena, de muerto: da ganas de llorar - y sobre todo, ese «ese» que nos sitúa patéticamente ante el morado, señalándolo directamente y haciendo sentir su presencia: es el morado que Miguel ve, el morado que le angustia y que hace que se sienta triste. Y, para colmo, Miguel ha sido rechazado por Mery y quiere beber: «sufrido: iya comienzo con lo mismo! Pretextos no faltan para llorar cuando estoy borracho. Ahora será el color morado el que me dé pena». Toda la pena de Miguel se refuerza a través de ese morado: desearía un escenario menos lúgubre: «Blanco o rojo sobre rostros morenos: mejor en cielo gris, bonito». Sería mejor un cielo «blanco o rojo sobre rostros morenos; ; pero ese morado sucio — lleno de connotaciones sensitivas — le resulta molesto. El pobre chibolo ${ }^{4}$ se siente solo y se culpa y avergüenza de sí mismo en un reiterativo pasaje en el que se encadena una expresiva y patética repetición del porque —la verdad, es que lloro porque soy cobarde. Cobarde: porque corro, porque tengo miedo de cumplir veinte años, porque tengo miedo de estar solo, porque ya no creo en mi collera ${ }^{5}$, porque lloré cuando me jalaron ${ }^{6}$ en el examen de ingreso a San Marcos, porque ese tal Pocho me la quita a Mery y yo no le pego-. Cobarde, solo, sin su grupo — su collera —, y para colmo jalado en el examen de ingreso a la Universidad. Pero lo peor, cobarde, porque otro muchacho le ha quitado a su Mery y él no ha sido capaz de vengarse. La cobardía es la peor mancha posible para los miembros de

\footnotetext{
$4 \quad$ El chiquillo.

5 Grupo de amigos.

6 Desaprobar un examen. De halar, naturalmente.
} 


\section{RAMÓN TRUJILLO CARREÑO}

una auténtica collera, formada siempre por muchachos, por delincuentes inocentes que no tienen otra ocupación que el robo o el vicio, jugando a ser esos «hombres mayores» a los que temen y admiran. Pero, en su soledad, es capaz de enternecerse y de dar rienda suelta a sus sentimientos reales, a su natural ternura de niño: "desde chibolo era cobarde. Tenía pena de las moscas. En verano, cuando mi vieja mataba moscas, no podia contener el llanto. Cuando en las noches los muebles, los libros, los cubiertos, los vasos se quedaban solos quería acompañarlos. Me encariñaba de las piedrecitas que encontraba en la calle. Las metía en el bolsillo y en la noche me acostaba con ellas, les daba calor con mi cuerpo para que no sintieran frio, para que no estuvieran solas. Un día traje de la calle un perro. Mi vieja lo botó. La casa es muy chica para perro..." Todo ternura; un sentimiento que no cabe ya en la cabeza de esos hombres mayores que admiran los chicos de la collera: «de todo lloraba. Todo me daba pena. Pero nunca nadie se dio cuenta de que yo estaba solo. Ni yo mismo». El sentimiento de ternura hacia los jóvenes débiles, perseguidos o marginados es una constante en las dos primeras novelas de Reynoso.

\section{LAS MUCHACHAS}

$\mathrm{L}$ as niñas, las chicas, presentan siempre las dos caras habituales en una sociedad pobre

en que se sienten fracasadas y humilladas: la desgana que produce un ambiente familiar que no coincide con sus ideales de muchacha moderna y, por el otro lado y para sí, el gusto de vivir, el placer de ser joven; así, sin más; solo el placer: estas niñas de las barriadas no tienen otras oportunidades vitales y solo el sexo o el alcohol puede llenar sus vidas o sublimar sus ilusiones. Veamos primero lo que le dice Bety, la hermana de Miguel, a su madre, y luego, lo que siente, piensa y calla:

«- ¡Siempre pescado con cebolla! ¿Ya no te he dicho mami que no me gusta? - dijo Bety. "—Cómo me gustaría que fueras a la paradita para que tú misma te convencieras de lo cara que está la carne!

La madre infeliz no entiende ni puede entender qué es lo que le sucede a su hija, ya en plena pubertad y llena de sueños lúbricos y de naturales ambiciones. Pero Bety sueña:

"Que si como pescado todo el santo día tendré ese maldito aliento en la boca y esta noche tengo que oler rico: a Coqui le gusta olerme: está que se muere de ganas, primero iremos a la procesión, 
luego le diré que me lleve al Embassy: bailaré pegadita a él, después que haga lo que quiera conmigo: y mañana seremos novios y dejaré esta casa que ya me tiene aburrida.

En realidad, no sabe lo que es el amor, pero está dispuesta a irse con el chico rico y entregarse a él; eso sí, en un ambiente lujoso, su gran sueño de niña pobre y desheredada:

"-Pero mami no te digo eso, compréndeme, es que... no sé cómo decirte, tú no me comprendes.

"—Lo que gana tu padre no alcanza para más — dice doña María sirviendo el pescado de una fuente a los platos.

La madre, infeliz, formada en otro tiempo y en otro medio, no entiende y no logra salir de su sentido común habitual. Pero la niña sigue con la miel de su ensueño:

"—Coqui tiene que sacarme de este infierno: me llevará a comer a la Pizzería de Miraflores, me traerá pasteles de la Tiendecita Blanca, nos iremos a un departamento de esos elegantes de edificio, con teléfono y todas las comodidades: tele, lavadora, aspiradora, refrigeradora y todas esas cosas eléctricas que son una maravilla; seré intima de sus hermanas y me vincularé con la gente decente de Miraflores, ya me veo hecha toda una señorita de sociedad.

La niña, en la inocencia de su sueño, quiere vivir las ilusiones que le han enseñado el mundo, el cine o la propaganda comercial. Es una víctima verdaderamente lastimera.

"-Seguro que esta noche se ve con el blanquiñoso, y no quiere ir apestando a pescado — comenta Miguel echando limón a su guiso.

„-Sí, sí: ipara lo que te importa!

Miguel sabe muy bien quién es Coqui: un señorito con dinero que quiere divertirse en el goce amoroso. Pero Bety está harta de su hermano.

"-Ya no tendré que soportar al borracho de mi hermano: „lo odio!, sucio que no le gusta lavarse los pies, todos en este barrio son sucios y apestosos: por eso lo dejé a Julio, antes yo también era cochina: no me importaba que el Julio viniera a verme con olor a cebolla en la boca, apestándole 
los pies, y con la camisa hedionda de sudor : hasta creo que me gustaba, pero Coqui me enseñó a ser limpia: mi Coqui anda siempre como recién salidito de la ducha.»

Bety quiere verse «fina» y diferente de los que, como su hermano, son sucios y apestosos.

Bety es muy representativa de los niños o muchachos que aparecen en esta novela. Se sienten castigados por la vida e, insensiblemente, se deslizan por el placer sin detenerse en las consecuencias, porque, al fin y al cabo, es lo único que pueden alcanzar. Los jóvenes de Reynoso están vistos como inocentes explotados que se dejan ir por la pendiente del placer, del sexo, de la pandilla, etc. Por eso he señalado ya esa sensualidad atractiva y atrayente, que se respira y - ¿por qué no? - que se disfruta en toda la novela: me he sentido niño, leyendo estos cuadros en que se cruzan dos puntos de vista diferentes. En ese mundo sucio y mísero que pinta, los jóvenes, que son inocentes por naturaleza, aunque estén absolutamente maleados o pervertidos, los sentimos siempre como revestidos de una tierna e incluso exquisita cualidad sensual. Y no es que haya perversidad en el relato, sino todo lo contrario, solo hay amor. De eso se trata: del gusto que da sentir, intuir, a esos jóvenes que solo pueden encontrar refugio en el sexo, en la bebida o en la pandilla. En la novela se contrastan dos puntos de vista opuestos y que acaso no resulten fáciles de ver para el lector. El hedonismo juvenil de aquellos inocentes — jóvenes desdichados — se hace contrastar con el nauseabundo comportamiento moral de los personajes adultos viciosos y homosexuales, como el rico y poderoso don $\mathrm{Manuel}^{8}$, dueño de empresas, fincas y casas y hombre de "peso» en el gobierno de la Nación. Pero esa inocencia de Bety, dispuesta a prostituirse sin sentir ni poder sentir amor en realidad, no pone reparos a la práctica sexual, en la que se refugia su fracaso infantil. En esta niña se halla una de las claves estéticas de la novela. Porque Bety no es mala: se limita a escapar de aquel infierno morado en que vive. En un mundo vacío de bienes del espíritu — lecturas, educación, afecto, formación—, esos jóvenes son modélicos, pues han encontrado una salida a sus males. ¡Claro que una salida provisional! Luego, la suerte, mejor o peor, los puede llevar a eso que ellos mismos considerarán en su momento como una vida honrada, honesta y normal. Bety no sabrá jamás qué es el amor y habrá de casarse seguramente algún día con un desgraciado como ella y será una madre

7 En América he oído construcciones con hediondo o jediondo, tanto con de como con a: jediondo a negra, 'oliendo mal por haber andado con alguna negra'.

8 Por eso, don Manuel es un personaje clave: representa la esclavización de los jóvenes y la ideología más reaccionaria que pueda imaginarse. 
conservadora y siempre asustada de que sus hijos caigan en la porquería callejera. Al fin y al cabo, estas Betys son luego, las honestas madres de otras Betys. Se pinta con estos niños del relato, igual que con los de la otra novela Los Inocentes, la inocencia infantil prostituida, sin que las víctimas lleguen a tener clara idea de su miseria. La inocencia violada, la inocencia prostituida, no puede ni podrá rehabilitarse jamás. El ideal de todas estas desdichadas Betys es, como ella misma dice, «ser unas señoritas»: ¡qué menos para lavar su pecado de inocencia!

\section{EL ZORRO}

$\mathrm{M}$

iguel Colmenares tiene un hermano un tanto «descarriado» que se llama Carlos y que es conocido como El Zorro. Un personaje novedoso en la novela: nos encontramos de pronto en la lectura con las genialidades de este muchacho, que de tonto no tiene un pelo.

«El Zorro vuelve a tocarse la curita adherida al dorso de su mano derecha:

„Y $Y$ usted, Colmenares, ¿qué tiene en la mano?, siempre lo veo con esa curita.

"-Nada, profe, es una cóbula.

"- ¿Cóbula?, esa palabra no existe" ${ }^{9}$ dirá usted, cábala.

"No, profe, cóbula.

"—Y qué significa?

"-El único que en el mundo sabe su significado soy yo, profe.

"- ¿Me lo puede decir?

"-No, profe, si se lo digo ya no es cóbula.

Y el profesor de castellano, riendo, se fue del corredor del segundo piso de la Unidad Escolar.

Toda esta magistral secuencia es de un valor incalculable. Humor, crítica, sensatez y, sobre todo, verdad... Verdad y ternura, como siempre, con los niños. En realidad se trata de un sabio comentario acerca del «concepto de significado» y sobre la estupidez academicista generalizada que reina, cada vez con mayor fuerza, sobre las ideas que se manejan cada día acerca del significado y sobre el malentendido general del concepto de corrección, que nada tiene que ver con la esencia del lenguaje, como sabe muy bien el autor. Es algo que se ve todos los días y cada vez con más frecuencia: las ideas del necio sobre el lenguaje. El

9 ¡Cuántas veces seguiremos oyendo la tozudez de muchos profesores y maestros! 
profesor dictamina pedantemente que cóbula «no existe» y que es seguro que se trata de una confusión con cábala, que, para él sí existe, pues está en el Diccionario. Lo primero que se le ocurre es el cantar de siempre: «no está en el Diccionario». Una respuesta que significa la más absoluta ignorancia de lo que es una lengua. Y así, el maestro le pregunta al Zorro qué significa cóbula, pero el muchacho, sabiamente, le recuerda al profesor que el único que en el mundo sabe su significado es él mismo, a lo que el profesor insiste en que se lo explique, en que se lo diga. Pero, el muchacho, con la sabiduría natural del que habla su propia lengua, afirma que, si se lo dijera, ya no sería cóbula. ¡Qué hermosa lección para los que creen que la verdad está en los diccionarios! La palabra, como decía Wittgenstein, es un hecho y nada más: el que esté en el diccionario o no, el que solo lo use una persona o varias o todas, es siempre algo absolutamente irrelevante. En rigor, El Zorro acaba de crear una nueva palabra ignorada por aquel profesor.

»El Zorro recuesta la cabeza en la carpeta y cierra, indolente, los ojos:

"- ¿Qué herida te has hecho en la mano?

"-No, mamá, no es nada.

"Entonces, ¿para qué te pones esa curita?

"-Por gusto, es mi cóbula.

"-Ya estás loco como tu hermano Miguel.

Ya en su casa, Carlos vuelve sobre la «curita» que usa caprichosamente y se la pone porque es su cóbula. ¿Hay algo más característicamente infantil que las invenciones particulares de palabras para uso propio y a veces secreto? La madre, naturalmente y con la inmadurez de la madurez, no entiende.

„El Zorro, sin levantar la cabeza de la carpeta, se queda mirando minucioso, el uniforme verde oscuro con botones dorados del instructor.

la victoria requiere el esfuerzo de gobernantes y gobernados de patrones y obreros de militares y civiles del comercio la banca la industria el clero y todas las fuerzas de la nación.

Sebito levanta la mano: 
"-Profe, profe, una pregunta.

"-El instructor deja de leer, levanta la cara y mira sostenido a Sebito.

"—Profe, ¿quiénes son las fuerzas vivas, $\mathrm{ah}^{10}$ ?

"-Los elementos representativos.

»-¿Y esos quiénes son, ah?

"-No haga preguntas tontas, atienda la lectura:

"la educación patriótica militar de la juventud estudiosa cumple sus fines primordiales al inculcar y exaltar la importancia y trascendencia moral de las virtudes militares.»

Otro niño, Sebito, escucha el típico discurso fascista de siempre y pregunta por «las fuerzas vivas»: ¿quiénes son? Pues según parece son los «elementos representativos» y el muchacho vuelve a preguntarse, naturalmente, quiénes son estos. Y, lo de siempre, la respuesta autoritaria y estúpida: «no haga preguntas tontas».

No conozco otro retrato tan preciso de la estupidez humana, de la necedad oficial.

\section{LA SENSUALIDAD}

La vivencia inocente del sexo llega a extremos increíbles con palabras dignas de la más alta poesía amorosa. Miguel recuerda exasperado a su Mery: «sus ojos abiertos, sus labios abiertos, agitados, y mis manos en sus piernas... Y su lengua alocada en mi boca y alocada en mis brazos...» Fuera del placer, nada bueno existe para todos estos jóvenes destruidos por la vida urbana.

«Miguel levanta la cabeza: Bety y Mery —serias, con el cuello estirado y los ojos bien abiertos, sin voltear la cara - pasan rozando la mesa. Miguel les dice:

»-_Putas! ¡REPUTAS!

10 Según el DRAE, que cree estar siempre en posesión de la verdad, en el uso americano se usa jeh! «preguntar, llamar, despreciar, reprender o advertir». Pero, en general, yo he oído ese ¡ah! del libro de Reynoso en el uso americano. Habría que ver cuál es la verdad. 


\section{RAMÓN TRUJILLO CARREÑO}

"Toma de un solo trago la cerveza de su vaso. Se queda mirando a las dos muchachas que, apuraditas y serias, se pierden entre la gente que transita por el portal.

"-Ya no la quiero, sí, de verdad, franco, sin mentira. A mi nadie me hace cojudo. Ya me viene el vómito, pero no por la cerveza; es ese maldito olor a pescado podrido: mejor huelo mis manos: tiene olor a mar, pero a mar limpio de verano con olor a Mery: de Mery tirada en la playa con los brazos abiertos. Bonita. Bonita. De verdad. Con los cabellos despeinados y relucientes de arena de Agua Dulce: fue el mejor verano de toda mi vida. Bonita que me daba miedo de mirarla, de mirarle sus ojos negros. Y aqui en el pecho, no: mentira, mas adentro, sentía fuego, candela, de alfileres encendidos en las venas. Y la sangre quemaba, hervía como arena. Y Mery reía en las olas, reía en las carpas de colores, reía mirando, mirándome. Reía a lo largo de todo ese verano. $Y$ ahora está de puta, de puta, reputa, como mi hermana. Y tanto cuidarlas. Y tanto hacerlas vigilar con la collera de mi hermano el Zorro.

El olor a mar, contrapuesto al olor a pescado podrido, es un bonito elogio sensual y sensitivo de la mujer. Mery olía a mar y Miguel «sentía fuego, candela, de alfileres encendidos en las venas». ¡Qué pureza de sentimientos, qué bien sentido el sentido del amor y del deseo en aquel pobre muchacho!

\section{DON LUCHO ${ }^{11}$}

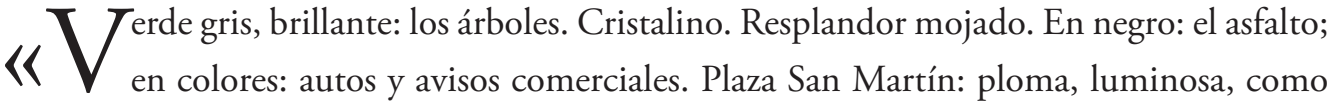
bomba de jabón. Aire maloliente a pescado podrido».

El paisaje y la perspectiva luminosa —en escalera descendente - de lo tonos de luz: a) luminoso: verde, gris, brillante, cristalino; b) mate: resplandor mojado; c) neutro: negro, asfalto, «en colores»: autos, avisos comerciales, ploma ${ }^{12}$, luminosa, bomba ${ }^{13}$ de jabón. Don

11 Un infeliz empleado del poderoso don Manuel.

12 Ploma, plomas, etc. Femeninos de plomo, en el uso adjetivo de este nombre.

13 ¿Bomba por pompa? Y ¿por qué no? Al fin y al cabo, la oposición sordo / sonoro no ha tenido verdadera vigencia en el espańol general. De acuerdo con estudios diversos, en los que he participado, la diferencia entre $[\mathrm{b}]$ y $[\beta]$ funciona de hecho en nuestra lengua como tensa / floja, de manera que abunda la confusión entre los sonidos de /b/y de /p/, por lo que, para un alemán, por ejemplo, nuestra /p/ se oye frecuentemente como [b]. Cf. Ramón Trujillo Carreńo, «Sonorización de sordas en Canarias», en Anuario de Letras, de la 
Lucho Colmenares, infeliz empleado del poderoso don Manuel se encuentra, en la mañana, con la imagen de una calle y de la Plaza de San Martín. El día está luminoso: los árboles, verde gris brillante y el día, cristalino y la humedad se ve ahora mate o no-brillante: un resplandor mojado. Y, en contraste con esto, surge lo neutro; el asfalto, autos y avisos comerciales y lo desagradable: se respira un aire maloliente a pescado podrido.

Lee la prensa: el cielo nublado. Ceniza. Y San Martín, gris verdoso, sobre su caballo brillante de lluvia tenue, fina. Don Lucho lee la prensa: «Disturbios de ayer dejan más de cien heridos y cuatro muertos», «Presidente anuncia nuevo gabinete», «EE. UU. envía cohetes a Vietnam», "Campesinos de Puno se alimentan con tierra. Hambruna en el sur», «Invaden hacienda en el Cusco». No hay más que malos augurios, cuyo carácter hemos señalado ya en la percepción de este relato.

\section{DON IMANUEL ${ }^{14}$ EOS CRUZADOS Y LOS SALVADORES}

Don Manuel se reúne con la gente importante: con los políticos, los banqueros y un general. ¡Se prepara un golpe de estado justamente este día del Señor de los Milagros!

„-Queremos ponerte al tanto del plan que pensamos emplear para traernos abajo al gabinete.

»-Perfectamente — contestó el general. El político sentándose al filo de la silla y moviendo sus manos de araña informó.

»-En un caserío de una hacienda de Cajamarca la policía sorprende a un extranjero sin documentación, con dólares, armas y cartas dirigidas a conocidos comunistas, después de hábiles interrogatorios este extranjero confesará que viene desde Cuba a tomar contacto con una supuesta guerrilla comunista.

"-Excelente — dijo el general.

»-Inmediatamente nuestros diarios destacarán la noticia, la Cruzada Nacionalista para el Desarrollo del País...

"El general lo interrumpió:

»-Y esa cruzada?

Universidad Nacional Autónoma de México, Vol. xvıII, 1980, pp. 247-254.

14 Don Manuel, que es homosexual, es además una persona de gran poder económico y de gran peso político en el gobierno del país. 
"—Don Manuel la ha organizado con gerentes amigos, servirá para despertar el sentimiento nacionalista, el amor al país, la protección a los productos nacionales $-\mathrm{y}$ moviendo nerviosamente las manos, concluyó-: en fin, para atacar al comunismo internacional y solapadamente al capital americano.

»-El jefe del partido en esto tiene mucha razón, pero no tanta —anotó el general—, en el fondo los gringos nos ayudan.

"-Como decía, esa cruzada exigirá al gobierno una acción enérgica, publicará varios comunicados contra esas doctrinas extranjeras que envenenan el espíritu de nuestra juventud, que siembran el caos, que destruyen a la familia peruana, en fin, todo lo que se dice en estos casos.

"-Pochito es todo un genio para esta clase de comunicados, un genio — dijo don Manuel moviendo su enorme cabeza calva.

"-Pondremos pues al gobierno en una peligrosa alternativa: o suspende las garantías y manda al Sepa a todo dirigente sindical o estudiantil con tinte rojo creando intranquilidad y desasosiego en la masa, o no hace nada y entonces tendrá que soportar el ataque frontal de las fuerzas democráticas y sobre todo del ejército por permitir y alentar la subversión comunista — concluyó el político acomodándose en la silla de playa.

"—De ésta sí que no se escapan — comentó el general tomándose de un solo trago su whisky.

Este pequeño fragmento es una pintura fiel de los abusos de las clases privilegiadas y de la intervención constante en el poder político y económico. Casi no necesita comentario, aunque, sin embargo, sí que tiene un interés especial, gracias a ese estilo que nada tiene que ver con el criterio estilístico seguido en la construcción de la novela. Su función es de nuevo una función de contraste; un poner a la vista y ante la inteligencia del lector la infinita diferencia que hay entre los «verdugos» y el pueblo que los padece, unas veces sufriente y otras, y como reacción, hedónico.

$\mathrm{H}$ e intentado hasta aquí llamar la atención sobre los aspectos formales o lingüísticoformales de este magnífico texto de Oswaldo Reynoso. Es cierto que su interés va mucho más allá de los aspectos que a mí me interesan, pero yo me he detenido en lo que me llama más la atención, que es el lenguaje. He dicho ya al principio que esta novela me parecía, antes que nada, una obra maestra «de lenguaje», con independencia de lo que 
pueda interesar a otros en relación con las fuentes literarias, con los aspectos típicamente gramaticales, con la literatura peruana o hispanoamericana en general, con las cuestiones relativas al léxico urbano de Lima, con las cuestiones de tipo sociológico, ético, etc. Yo he escrito estas cuartillas sobre el lenguaje de En octubre no hay milagros atendiendo al material con que está construido el texto, que es el castellano y su gramática, el castellano que usaron César Vallejo o Juan Ramón Jiménez. En mi opinión, no se puede estudiar la literatura sin conocer a fondo las estructuras lingüísticas del idioma en que esté escrita. No se pueden analizar las características lingüísticas de un trabajo rigurosamente idiomático, como es siempre una novela, sin tener los conocimientos lingüísticos que tienen que ver directamente con la estructura o forma en que han sido organizados los textos. Cada texto contiene su propia teoría ${ }^{15}$; es decir, su propia forma, que es idiomática. Y no se puede analizar un texto lingüístico dejando de lado los aspectos estrictamente idiomáticos, porque eso supondría desdeñar lo esencial, el material léxico y las reglas que ordenan y organizan el objeto literario. La idea de forma, a la que dio un especial empuje Ferdinand de Saussure, se ha transformado en la clave para el entendimiento completo de lo "poético», es decir, de lo creado con una lengua determinada. Porque la individualidad de una obra literaria no está en eso que se llama fondo, asunto o argumento sino en su forma idiomática. Nociones como esas de fondo, asunto o argumento son conceptos que se refieren a las realidades que suponemos narradas en los textos; pero que nada tienen que ver con la esencia de ellos, sino con realidades que están fuera de ellos. Cuando hablo de forma, lo hago en el sentido de los formalistas rusos y, particularmente, de las ideas básicas de Saussure ${ }^{16}$, según el cual los signos están constituidos solo por diferencias: «la lengua es una forma y no una sustancia. Nunca nos percataremos bastante de esta verdad, porque todos los errores de nuestra terminología, todas las maneras incorrectas de designar las cosas de la lengua provienen de esa involuntaria suposición de que hay una sustancia en el fenómeno lingüístico» ${ }^{17}$. Saussure inaugura la modernidad del pensamiento sobre el lenguaje al distinguir entre

15 En el Prólogo de su Gramática, decía don Andrés Bello, el más grande de los gramáticos, americanos o españoles, de todos los tiempos, que «cada lengua tiene su teoría particular, su gramática [...]. Esta misma palabra idioma está diciendo que cada lengua tiene su genio, su fisonomía, sus giros». Cf. Gramática de la lengua castellana destinada al uso de los americanos. Edición crítica y Estudio de las variantes, de Ramón Trujillo Carreño, Instituto de Lingüística «Andrés Bello», Santa Cruz de Tenerife, España, 1981, p. 124.

16 Cf. Ferdinand de Saussure, Curso de lingüistica general, traducción de Amado Alonso, Losada, decimosegunda edición, Buenos Aires, 1945.

17 Saussure, op. cit., Segunda Parte, cap. 4. 


\section{RAMÓN TRUJILLO CARREÑO}

forma y sustancia: la forma pertenece a la lengua; la sustancia, a la realidad extraidiomática. Por ello, eso que llamamos argumento, fondo o asunto no representan el significado de un texto, sino las cosas que imaginamos como representadas en el texto y que, de acuerdo con las opiniones de los lectores, nunca son iguales. Por eso no me cansaré de repetir que los textos literarios no «quieren decir», sino que, por el contrario, «dicen». Una cosa es lo que yo piense de En octubre no hay milagros y otra cosa "lo que ese texto es como tal texto». En uno de los fragmentos de la obra de Nietzsche que se han ido publicando después de su muerte, se leen estas luminosas palabras: «se es artista al precio de sentir como contenido, como la cosa misma, lo que todos los no artistas llaman forma» ${ }^{18}$. Una idea fundamental para aclarar esta cuestión del fondo frente a la de referente o argumento, tan mal comprendidos por la mayoría de los estudiosos, tanto lingüistas como críticos literarios. Es una idea que representa el único punto de vista válido en una indagación sobre el lenguaje, pues enseña a) la confusión vulgar entre contenido o significado, de una parte, y fondo, asunto o argumento, de otra; es decir, entre lo que «se dice» (significado, forma) y lo que «se quiere decir» (asunto).

Por eso no he querido entrar aquí en lo que podríamos llamar «argumento» o «asunto» de esta magnífica novela En octubre no hay milagros, sino señalar algunos de los aspectos más interesantes desde el punto de vista del texto mismo, sin otras consideraciones sociológicas, históricas o psicológicas, que, aun siendo importantes, no tienen nada que ver con este texto en tanto que tal texto. No se trata aquí del argumento o asunto, sino del texto propiamente dicho, que no es una sustancia sino una forma.

Reynoso, Oswaldo. En octubre no hay milagros. Buenos Aires (Argentina): Ediciones El Andariego, [1965] 2008.

18 Cf. Sämtliche Werke, Kritische Studien Ausgabe, Deutscher Taschenbuch Verlag / De Gruyter, München, 1988, Vol. 13. Apud Agustín Izquierdo, Prólogo del libro Estética y teoría de las artes, en el que se recogen, clasifican y estudian fragmentos de la obra de Friedrich Nietzsche, Tecnos, Madrid, 1999, p. 26. 